\title{
Evaluation of Dredged Sediment as a Silt and Clay Source for Artificial Tidal Flats
}

\author{
Satoshi NAKAI ${ }^{*}$, Daizo IMAI ${ }^{* *}$, Ryo ISHII ${ }^{* * *}$, Yoichi NAKANO ${ }^{* * * *}$, \\ Wataru NISHIJIMA ${ }^{* * * * *}$ and Mitsumasa OKADA* \\ * Department of Chemical Engineering, Hiroshima University, Hiroshima 739-8527, \\ Japan \\ ** Department of Chemistry for Materials, Mie University, Mie 514-8507, Japan \\ *** Sanyo Techno Marine Inc., Tokyo 103-0012, Japan \\ **** Department of Chemical and Biological Engineering, Ube National College of \\ Technology, Yamaguchi 755-855 Japan \\ ***** Environmental Research Center, Hiroshima University, Hiroshima 739-8513, Japan
}

\begin{abstract}
This research was carried out to investigate the feasibility of using dredged sediment (DS) as the additive of silt and clay for artificial tidal flats. A series of experiments conducted in the real seashore and in a tidal flat simulator demonstrated that DS could be used for artificial tidal flats. Furthermore, the tidal flat simulator experiment showed that the macrobenthos population increased with the DS addition. However, use of conditioners made of paper sludge and poly-aluminum chloride for DS granulation treatment was associated with a time lag in the growth of the macrobenthos: these agents may be released during the course of the experimental period. Possible reasons for the increased polychaete and gastropod abundances in the artificial tidal flats might be an increase in supplied organic matter and stimulated benthic microalgae growth due to the DS addition. Finally, a growth test was carried out for the short neck clam Ruditapes philippinarum, which showed that it can grow in artificial tidal flats to which DS has been added. Too much DS, however, may suppress its growth.
\end{abstract}

Keywords: artificial tidal flat, benthic ecosystem, dredged sediment.

\section{INTRODUCTION}

In the 1940s, the total area of natural tidal flats in Japan was approximately 82,600 ha. By the 1980s, however, about 40\% had unfortunately disappeared (Kimura, 1994). In recent years, useful functions of tidal flats such as biological production, water quality clarification and recreation have been recognized more and more (Miyoshi et al., 1991; Kimura et al., 1992; Imamura, 1997; Evans et al., 1998; Ishii et al., 2001; Morrison et al., 2002; Tiner et al., 2003; Sakamaki et al., 2006; Magni and Montani, 2006). For example, Kimura et al., (1992) compared water quality at the seashore where an artificial tidal flat existed, and its offing region. They found that COD in the seashore was significantly lower than that in the offing region. This difference in the water quality in the investigated area was accounted for by increased capability of the artificial tidal flats for degrading organic matter. Benthic organisms have been investigated as the cause of the water clarification capability of artificial and natural tidal flats (Miyoshi et al., 1991, Imamura, 1997). Because such useful functions have highlighted the importance of tidal flats, in 2003 the Japanese government enacted a law for the promotion of nature restoration, which charges those engaged in development activities in coastal areas with mitigation of damage to or lost of tidal flats.

Artificial tidal flats have been constructed at many sites in Japan (e.g. Imamura, 1997;

Address correspondence to Satoshi NAKAI, Department of Chemical Engineering, Hiroshima University, Email: sn4247621@hiroshima-u.ac.jp

Received 17 February 2009, Accepted 7 July 2009 
Hosokawa, 1997; Lee et al., 1997; Lee et al., 1998). However, surveys in Hiroshima Bay showed that many of the artificial tidal flats did not have the same physicochemical and biological structures as natural tidal flats, and that silt accumulation in the sediment is a key parameter for the creation of a natural-like artificial tidal flat (Lee et al., 1997; Lee et al., 1998). Bolam and Whomersley (2005) reported a significant relationship between silt and clay content and number of macrobenthos species in the constructed mudflats. Therefore, to accomplish their purpose (e.g. the recovery of a clam fishery and feeding area for birds), construction of artificial tidal flats must establish the sediment environment suitable for the benthic ecosystems.

Selection of sediment media for the construction of artificial tidal flats may be the primary factor controlling the sediment environment. In the conventional construction of artificial tidal flats, dredged sediment (DS) would be used as basement material to infill the core, because DS is the waste discharged from harbor management activities. The basement material would be covered with sandy media such as mountain or sea sands. However, compared with natural tidal flats, the biota appearing in the artificial tidal flats constructed by such a method was often poor because of low silt (particles with diameter less than $75 \mu \mathrm{m}$ ) content (Lee et al., 1998). Generally, DS mostly consists of silt and contains abundant nutrients, such as organic matter, nitrogen, and phosphorus (Bruland et al., 2006). This suggests that the DS has a potential to be a good additive for the surface of the artificial tidal flat, supplying silt, clay and nutrients for improving the tidal flat ecosystem. An essential task is to investigate how DS addition to the sandy media affects the emerging tidal flat ecosystems.

This research was carried out to assess the feasibility of using DS as the additive for construction of artificial tidal flats. Artificial tidal flats were constructed in a tidal flat simulator and at the real seashore using mixtures of DS and sandy sediment media. The emerging benthic communities and physicochemical characteristics were analyzed. Because the short neck clam Ruditapes philippinarum is one of the most important macrobenthic fishery products in artificial tidal flats in Japan, a growth test of $R$. philippinarum was also carried out in DS mixtures.

\section{MATERIALS AND METHODS}

\section{Artificial tidal flats in real seashore}

Five artificial tidal flats (E1-E5) with $10 \mathrm{~m}$ length, $2 \mathrm{~m}$ width, and 1/100 slope were constructed in March 2005 in the Tategami area of Ago bay, Mie prefecture, Japan (Fig. 1). As the sediment media, sea sand and DS both excavated from Ago Bay were used. Prior to use, the DS was granulated using various conditioners to make practical handling easier. These conditioners were made of: paper sludge (PS, Imai et al., 2006) (E1 \& E2); gypsum (E4); poly-aluminum chloride (PAC) as well as waste steel slag (WSS) (E5). A natural tidal flat (C3) at the same tidal level was chosen as a reference for monitoring benthic communities as well as physicochemical characteristics. The sediment media used to construct the artificial tidal flats are summarized in Table 1. The DS mostly (98\%) consisted of silt and clay particles with diameters less than $75 \mu \mathrm{m}$. 


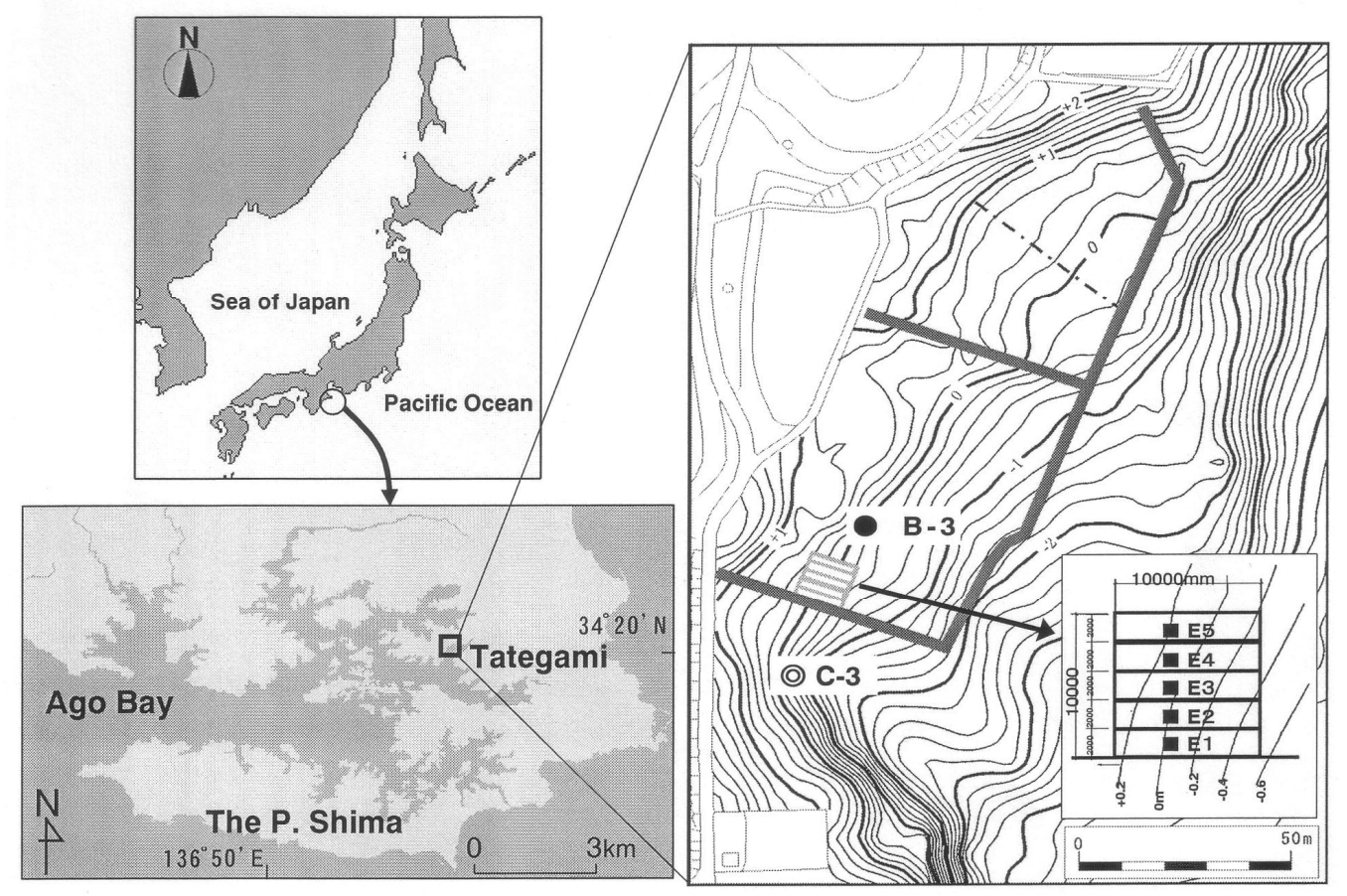

Fig. 1 Location of the artificial and natural tidal flats in Tategami, Ago bay, Mie, Japan.

Table 1 Sediment of artificial tidal flats in real seashore.

\begin{tabular}{cccccc}
\hline Run & E1 & E2 & E3 & E4 & E5 \\
\hline $\begin{array}{c}\text { Granulation of } \\
\text { DS }\end{array}$ & $1.5 \mathrm{wt} \%$ PS & $21.5 \mathrm{wt} \%$ PS & - & $5 \mathrm{wt} \%$ gypsum & $\begin{array}{c}2 \mathrm{wt} \% \text { PAC \& } \\
\text { WSS }\end{array}$ \\
\hline Sediment & $\begin{array}{c}3: 7 \\
\text { DS*:Sediment }\end{array}$ & $\begin{array}{c}3: 7 \\
\text { DS*:Sediment }\end{array}$ & Sea sand & $\begin{array}{c}3: 7 \\
\text { DS*:Sediment }\end{array}$ & $\begin{array}{c}3: 7 \\
\text { DS*:Sediment }\end{array}$ \\
\hline
\end{tabular}

*Granulated DS as indicated in this table.

\section{Artificial tidal flats in a tidal flat simulator}

In order to verify the results obtained by the real seashore experiments, in April 2005 artificial tidal flats were constructed in a tidal flat simulator using DS and a sandy medium (Fig. 2). Wave and tide conditions in Hiroshima bay (Table 2) were reproduced. These artificial tidal flats were of $4.5 \mathrm{~m}$ length, $0.8 \mathrm{~m}$ width, and 3/100 slope. In this trial, PS treated DS, PAC treated DS, and untreated DS were each mixed with mountain sand (1.6\% silt and clay) to achieve $25 \%$ of silt and clay content (Table 3 ). This silt clay content is within the range of values observed in the five artificial tidal flats (E1-E5) of the seashore experiment. Mountain sand (MS) was used because of its importance as the alternative to sea sand which is of limited availability. Mining of sea sand is prohibited in some prefectures in Japan to avoid disturbance of the coastal ecosystems (Takeoka, 2002). In addition to these 3 mixtures, a control tidal flat was made using natural tidal flat sea sand with $25 \%$ silt and clay content obtained from Hiroshima bay, Japan. Prior to use, the natural tidal flat sea sand was dried. We inoculated the artificial and control tidal flats with benthic communities collected by sieving through a $1-\mathrm{mm}$ mesh sieve a $10 \mathrm{~cm}$ depth core $\left(0.4 \mathrm{~m}^{2}\right.$ surface area) from a natural tidal flat in Hiroshima Bay, Japan. 


\section{Benthic ecosystems}

We chose as indicators benthic microalgal growth and the species diversity and abundance of macrobenthos emerging in the artificial tidal flats. These are both important components of the benthic ecosystem. Benthic microalgae are primary producers in tidal flats (McConnaugley \& McRoy, 1979; Herman et al., 1999; Posey et al., 2006). Macrobenthos are near the bottom of the food web, providing food for large crustaceans, fish and birds (Day et al., 1989; Evans et al., 1998), and also play a role in water purification by the tidal flats (Herman et al., 1999; Magni and Montani, 2006). Certain bivalves, such as clams, form fisheries (Ishii et al., 2001). To survey the emerging macrobenthos, we periodically sampled the artificial tidal flat with sediment core samplers: $25 \mathrm{~cm} \times 25 \mathrm{~cm} \times 25 \mathrm{~cm}$ for the real sea shore and $10 \mathrm{~cm} \times 10 \mathrm{~cm} \times 10$ $\mathrm{cm}$ for the tidal flat simulator. We sieved the sediment sample through a 1-mm-mesh screen and preserved the retained macrobenthos in $10 \%$ formalin. The specimens were then identified by microscopic observation to the lowest practicable taxonomic level. Benthic microalgal biomass in a 1-cm-thick surface layer was measured using the $90 \%$ acetone extraction method (SCOR/UNESCO, 1966).

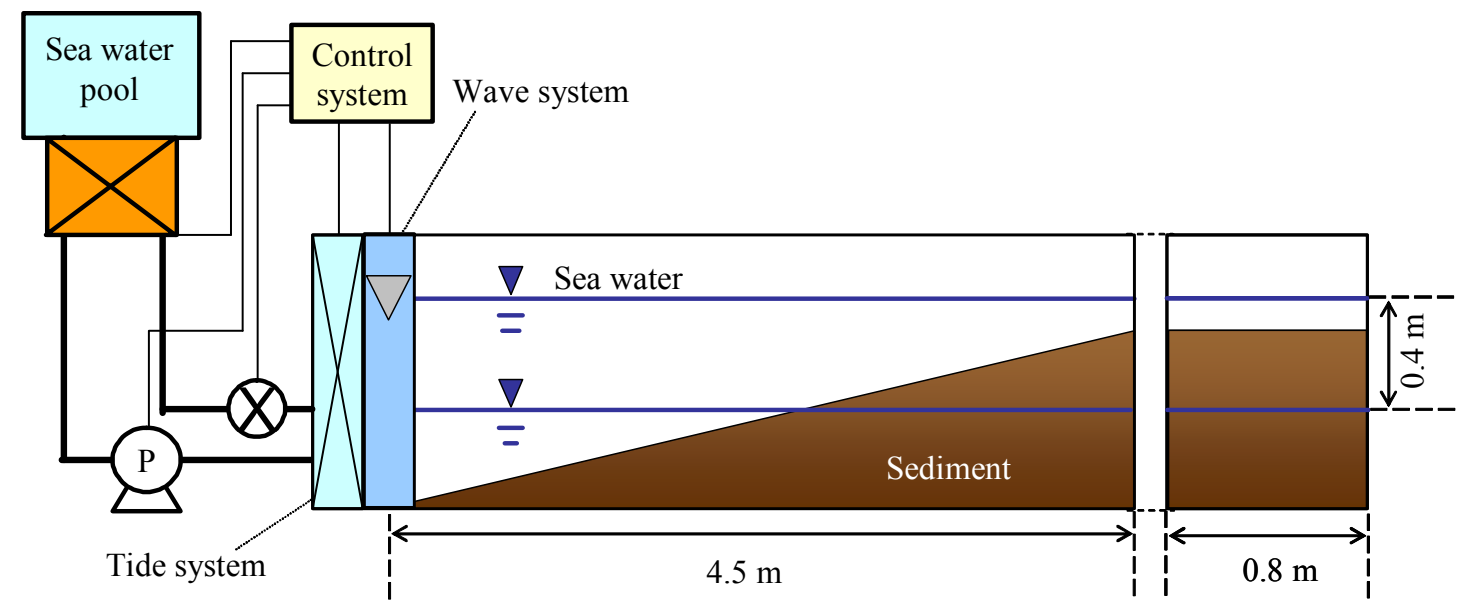

Fig. 2 Schematic view of the tidal flat simulator.

Table 2 Operating conditions of the tidal flat simulator.

\begin{tabular}{cc}
\hline Wave period & $0.8 \mathrm{~s}$ \\
\hline Wave height & $10 \mathrm{~mm}$ \\
\hline Tidal amplitude & $40 \mathrm{~cm}$ \\
\hline Tidal period & $12 \mathrm{~h}$ \\
\hline
\end{tabular}

Table 3 Sediment of artificial tidal flats in the tidal flat simulator.

\begin{tabular}{ccccc}
\hline Run & Control & MS/UT-DS & MS/PS-DS & MS/PAC-DS \\
\hline $\begin{array}{c}\text { Granulation of } \\
\text { DS }\end{array}$ & - & Untreated & $1.5 w \%$ PS & 2wt\% PAC \\
\hline Sediment & Sea sand & $\begin{array}{c}\text { Mixture of MS } \\
\text { and DS* }\end{array}$ & $\begin{array}{c}\text { Mixture of MS } \\
\text { and DS* }\end{array}$ & $\begin{array}{c}\text { Mixture of MS } \\
\text { and DS* }\end{array}$ \\
\hline
\end{tabular}

*Untreated or granulated DS as indicated in this table.

\section{Sediment environment}

To understand the relationship between the benthic ecosystems and the sediment 
characteristics influenced by the addition of DS, we characterized the sediment environment with the following parameters: oxidation-reduction potential (ORP); hydraulic conductivity; particle size distribution; ignition loss; total and available nitrogen and phosphorus contents. The vertical profile of the ORP was measured by inserting electrodes into the artificial and control tidal flats, while a falling-head permeameter (DIK-4050, Daiki Rika Kogyo, Japan) was used to determine hydraulic conductivity of sediment. Particle size distribution and ignition loss of the sediment were analyzed according to Japanese Industry Standards (JIS)-A1204 and A1226, respectively. In accordance with JIS-A1204, we pretreated the sediment samples with $30 \%$ hydrogen peroxide to break up sediment aggregates, and then wet sieved them through $75 \mu \mathrm{m}, 106 \mu \mathrm{m}, 250 \mu \mathrm{m}, 425 \mu \mathrm{m}, 850 \mu \mathrm{m}$, and $4750 \mu \mathrm{m}$ mesh sieves. We determined total nitrogen in the sediment samples by the Kjerdahl nitrogen neutralization titration method after degradation of organic matter in the sediment with $96 \%$ sulfuric acid. For the measurement of total phosphorus, we treated the samples with $65 \%$ nitric acid and $60 \%$ perchloric acid, and then determined total phosphorus by the molybdenum blue method (MOE, 1996). Available phosphorus was determined as acid extractable phosphorus using Truog's method (Truog, 1930) in which phosphorus was extracted with $0.002 \mathrm{~N}$ sulfuric acid, followed by determination using ammonium molybdate, antimony potassium tartrate, and ascorbic acid.

\section{Growth of a short neck clam}

The short neck clam, Ruditapes philippinarum, was cultivated in mixtures of untreated DS and mountain sand to investigate the effect of DS addition to the sandy medium on its growth. Since a preliminary experiment suggested that too much silt and clay content was not good for the growth of $R$. philippinarum (data not shown), we decided to use mixtures of mountain sand and DS giving 5\% and 10\% silt and clay content. We placed $5 \mathrm{~cm}$ depth of these mixtures into $10 \mathrm{~L}$ aquaria into which sand-filtered seawater flowed. 30 individuals of $R$. philippinarum with about $12 \mathrm{~mm}$ of shell length were inoculated in these. During the experimental period (3 months), we monitored numbers of surviving individuals and their shell length.

\section{RESULTS AND DISCUSSION}

\section{Macrobenthos in the artificial and natural tidal flats in the real seashore}

Figure 3 shows the observed variation in the macrobenthos population in the 5 artificial tidal flats and the natural tidal flat. The abundance of macrobenthos in the 5 artificial tidal flats increased after May 28 and finally exceeded that in the natural tidal flat. This indicates the migration of macrobenthos into the 5 artificial tidal flats and/or growth of macrobenthos in the sediment media. Among the 4 artificial tidal flats to which DS was added, E4 (containing the gypsum-treated DS) showed a relatively low population. The macrobenthos abundances in the other 3 artificial tidal flats constructed using PS- and PAC-treated DS (E1, E2, and E5) were comparable to that in E3 as well as the natural tidal flat (C3). Also, the distribution of gastropods, polychaetes and bivalves was consistent in the artificial and natural tidal flats. These results indicate that DS can be used as an additive to the sandy medium for construction of artificial tidal flats.

It should be noted that the macrobenthos population in $\mathrm{E} 3$ became higher than $\mathrm{C} 3$, even though E3 was constructed using natural sea sand obtained from Ago bay. One possible 


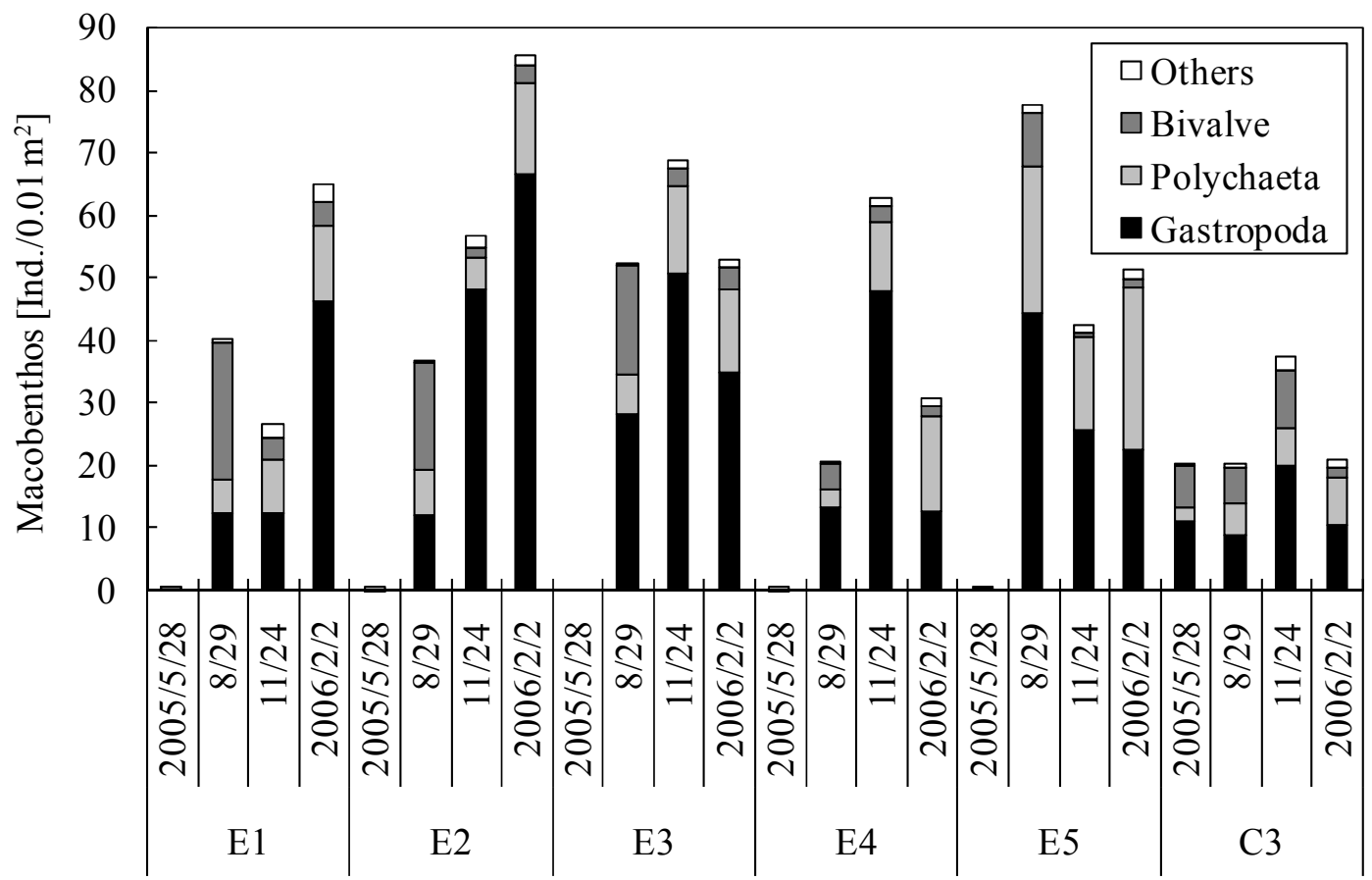

Fig. 3 Variation in the emerging macrobenthos population in the 5 artificial (E1-E5) and natural (C3) tidal flats constructed in March 2005 in Tategami, Ago bay, Japan. The value indicates the average $(n=2)$.

reason may be the difference in silt and clay content. As shown in Table 4, the silt and clay content in E3 was about 15-30\%. Although the silt and clay content (64\%) in C3 was measured only once during the experimental period, an additional measurement carried in 2006/9 showed $67.3 \%$ of silt and clay content in C3. This indicates that too much silt and clay might possibly have a negative impact on the macrobenthos population. The silt and clay content in the other four artificial tidal flats varied to some degree. For example, the highest value in E5 was 26.0\%, whereas the lowest one in E1 was $33.3 \%$. Due to this inconsistency, we could not evaluate the effects of different granulation agents on macrobenthos population.

Another possible reason for the difference of macrobenthos population between E3 and C3 may be high numbers of invisible larvae and eggs of macrobenthos in the sediment media used for the construction. Although the observation on May 28 showed quite low macrobenthos population, invisible larvae and eggs were not measured.

Table 4 Silt and clay $(<75 \mu \mathrm{m})$ content [\%] of the sediment samples in the artificial and natural tidal flats.

\begin{tabular}{rcccccc}
\hline \multicolumn{1}{c}{ Time } & E1 & E2 & E3 & E4 & E5 & C3 \\
\hline $2005 / 4$ & 35.6 & 28.0 & 16.9 & 36.1 & 25.7 & NA $^{\mathrm{a}}$ \\
\hline 6 & 45.1 & 22.6 & 28.8 & 26.3 & 19.3 & 64.1 \\
\hline 10 & 33.3 & 20.0 & 15.2 & 23.4 & 20.3 & NA $^{\mathrm{a}}$ \\
\hline $2006 / 2$ & 43.6 & 43.3 & 29.1 & 45.8 & 26.0 & $\mathrm{NA}^{\mathrm{a}}$ \\
\hline
\end{tabular}

${ }^{\mathrm{a}}$ Not available 
The results supported the use of DS as an additive to a sandy medium for construction of artificial tidal flats. However, due to the variation in silt and clay content between E1-E5 and C3, further investigation is still needed to reveal the effects of granulated DS addition on the macrobenthos population.

\section{Macrobenthos in the artificial tidal flats in the tidal flat simulator}

We constructed 3 artificial tidal flats with $25 \%$ silt and clay content using the mixture of mountain sand (MS) and PS treated, $2 \mathrm{wt} \%$ PAC treated, or untreated (UT) DS respectively, and used natural sea sand for a control tidal flat. As shown in Fig. 4, the silt and clay content of the three artificial tidal flats was successfully adjusted to $25 \%$, although the control tidal flat contained a greater medium sand fraction.

A reduction zone developed beneath the surface of the control tidal flat as well as all artificial tidal flats (regardless of the granulation treatment of the DS) (Fig. 5). The ignition loss of sediment samples of these control and artificial tidal flats were $2.8 \%$ and $4.0-5.4 \%$ respectively, while that of the MS itself was $0.95 \%$. This confirmed that the addition of DS resulted in enrichment of organic matter. However, the hydraulic conductivity in these tidal flats 5 months after construction was almost same: $1.3 \times 10^{-5}$ $\mathrm{cm} / \mathrm{s}$ in the control tidal flat and about $1.0 \times 10^{-5} \mathrm{~cm} / \mathrm{s}$ in the artificial flats. These values may account for the occurrence of a reduction zone in the artificial and control tidal flats.

It should be noted that changes over time in the hydraulic conductivity were observed in the artificial tidal flats to which PAC-DS and PS-DS were added. Although the value after 5 months of the construction was about $1.0 \times 10^{-5} \mathrm{~cm} / \mathrm{s}$ as mentioned before, the hydraulic conductivity soon after the construction was $7.5 \times 10^{-5} \mathrm{~cm} / \mathrm{s}$ for the mixture MS/PAC-DS and $1.1 \times 10^{-4} \mathrm{~cm} / \mathrm{s}$ for the mixture MS/PS-DS. When UT-DS was used, the value was consistent at $9.9 \times 10^{-6} \mathrm{~cm} / \mathrm{s}$. This suggests the possible diffusion of PAC and PS during the experimental period.

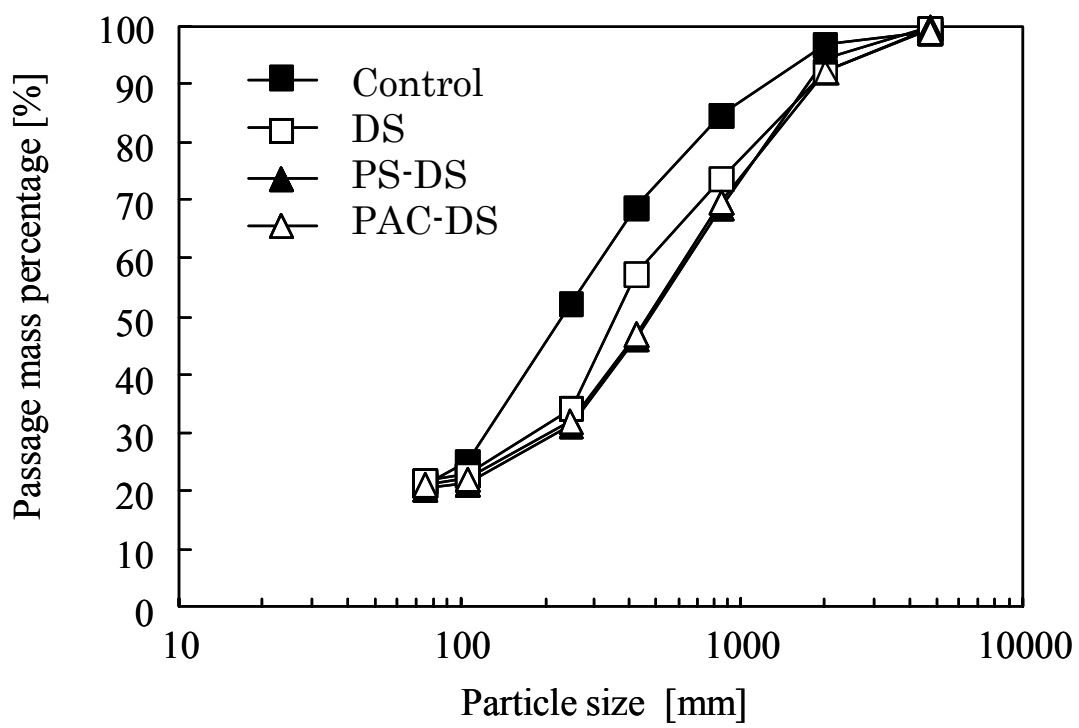

Fig. 4 Cumulative particle size curves of the sediments in the artificial and control tidal flats. 


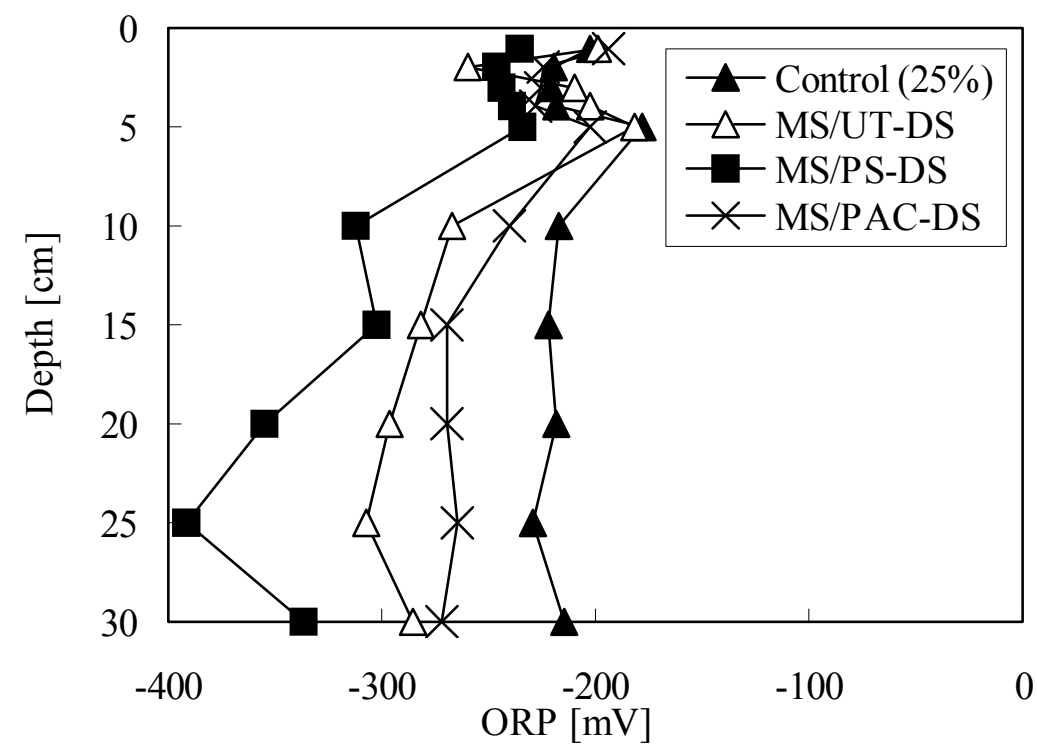

Fig. 5 Vertical profile of ORP in the control and artificial tidal flats. The values in the legend indicate the silt content.

Figure 6 shows variation in macrobenthos abundance. This was lowest in the control tidal flat and almost steady during 159 days of experimental period. Furthermore, two of the artificial tidal flats attained abundances greater than 40 ind. $/ 0.01 \mathrm{~m}^{2}$, being more than twice that of the control tidal flat. This result confirmed the feasibility of using DS as the additive to sandy media for increasing the macrobenthos population. Since the experimental conditions were different, we could not compare in detail this result with that obtained in the real seashore experiment. However, both experiments consistently indicate that DS could be used as a silt and clay source for construction of artificial tidal flats.

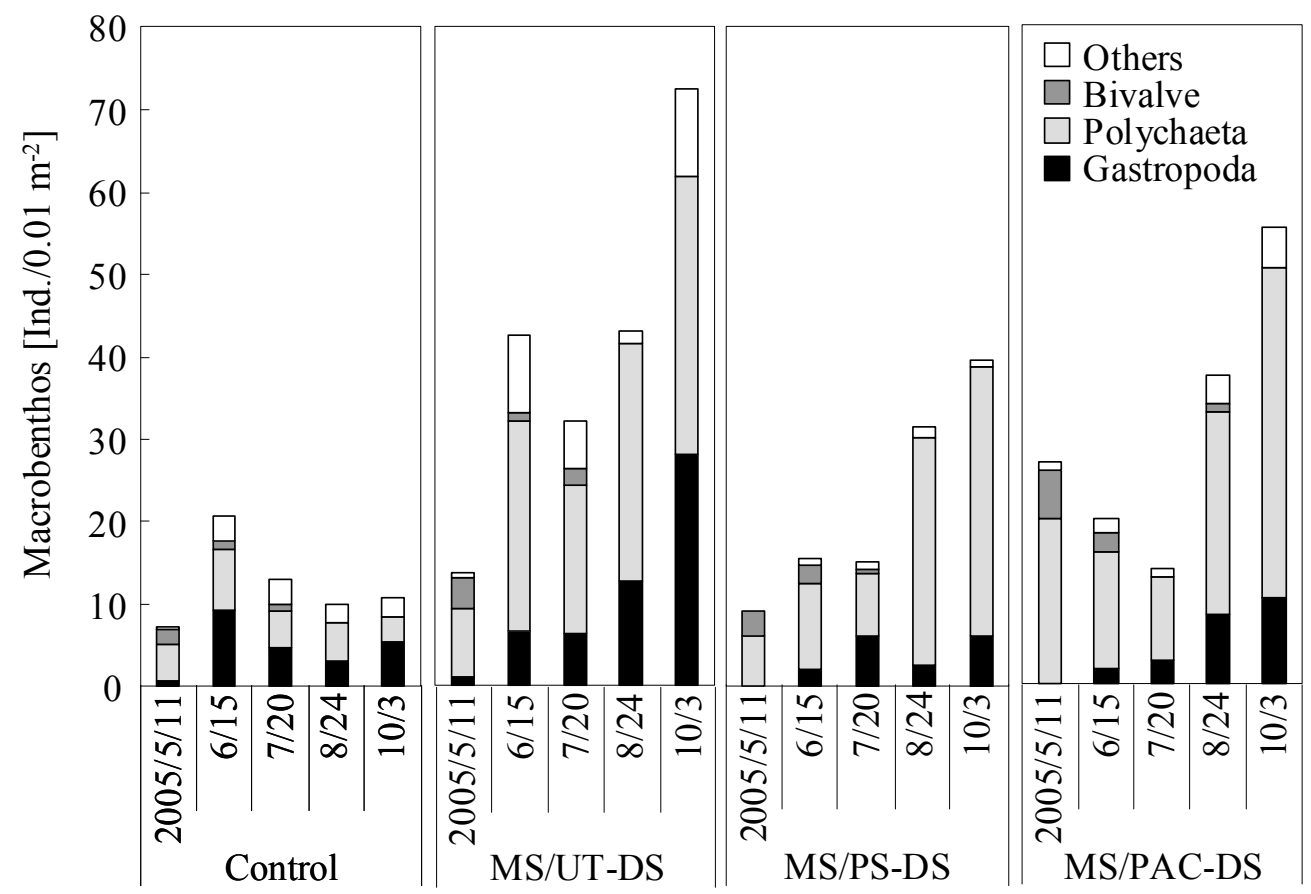

Fig. 6 Variation in the population of macrobenthos emerging in the control and artificial tidal flats with $25 \%$ of silt-content. 
Although the macrobenthos abundance increased after $11^{\text {th }}$ May in the artificial tidal flat to which UT-DS was added, where PS-DS and PAC-DS were used, the population did not increase till $20^{\text {th }}$ July. As mentioned before, the measurements of hydraulic conductivity indicated the possible diffusion of PS and PAC during the experimental period. Possibly PAC and PS themselves and/or the granulated figuration might be the cause of this delay, and PAC-DS and PS-DS might act as UT-DS after diffusion of these agents.

The greatest abundance of macrobenthos was observed in the artificial tidal flat to which UT-DS was added (72.3 Ind./0.01 $\mathrm{m}^{2}$ ), the dominant species being the polychaetes Ceratonereis erythraeensis (17.0 Ind./0.01 $\left.\mathrm{m}^{2}\right)$ and Capitella sp. (14.4 Ind. $/ 0.01 \mathrm{~m}^{2}$ ) and a gastropod Batillaria cumingii $\left(26.0 \mathrm{Ind} . / 0.01 \mathrm{~m}^{2}\right)$. Together these accounted for about $80 \%$ of the total abundance of macrobenthos. Furthermore, the dominance of these species was consistent in the three artificial and control tidal flats (data not shown).

\section{Effect of DS addition on benthic ecosystems}

Organic matter in a tidal flat provides a substrate for certain microorganisms and macrobenthos (Brown and McLachlan, 1990; Herman et al., 1999). Ignition loss measurements showed that the addition of DS to MS resulted in the enrichment of organic content in the artificial tidal flats. Furthermore, greater benthic microalgal growth was observed in the artificial tidal flats to which DS was added compared with the control (Fig. 7).

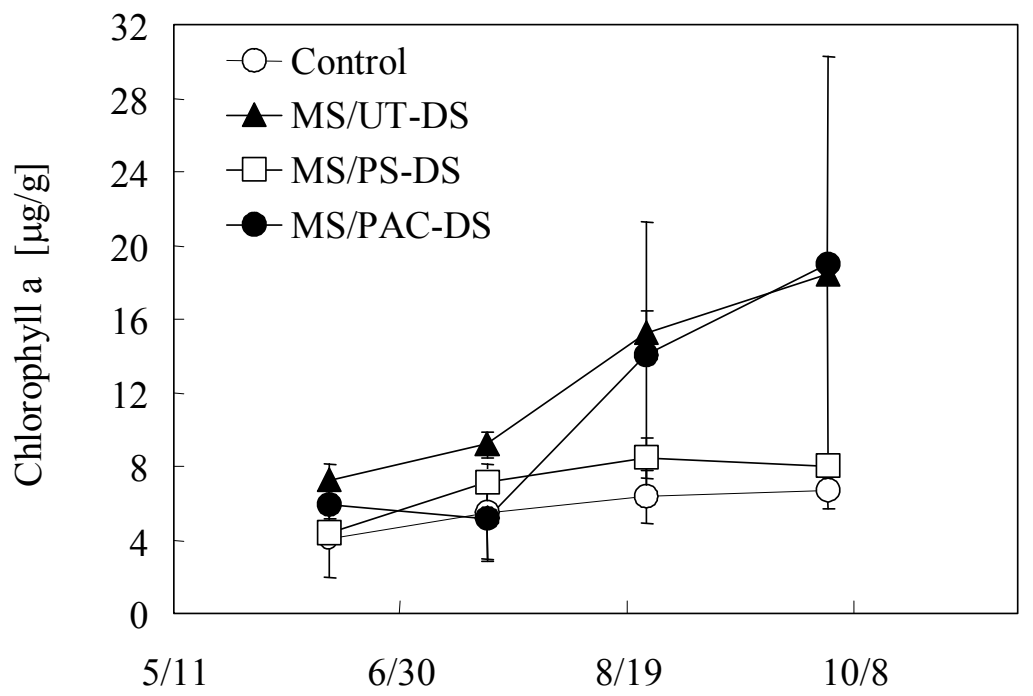

Fig. 7 Changes in chlorophyll a in the artificial tidal flats. Bars indicate standard deviation $(\mathrm{n}=3)^{*}$ and differences between the average and measured value $(\mathrm{n}=2)^{* *}$.

The polychaetes $C$. erythraeensis and Capitella sp. were two of the three dominant species in the artificial tidal flats in the tidal flat simulator (Fig. 6). Polychaetes are commonly occurring species that feed on particulate organic matter (Brown and McLachlan, 1990), and the abundant organic matter and higher concentration of benthic microalgae in the artificial tidal flats would be the main factors supporting the high macrobenthic biomass. The gastropod $B$. cumingii was also a dominant species in the 
artificial tidal flats. Certain species of Batillariidae are known to utilize microalgae on the substrate. Measurement of chlorophyll a on the surface of the artificial tidal flats confirmed that addition of DS stimulated benthic microalgal growth. This suggests that $B$. cumingii dominance was caused by the stimulated benthic microalgal growth. It has been reported that nutrient addition to sediment in an experimental sediment plot resulted in stimulated growth of a gastropod Hydrobia sp. as well as benthic microalgae, and a temporal increase in Hydrobia sp. abundance (Posey et al., 2006).

Possible causes for the stimulated benthic microalgal growth are the abundant nutrients and trace elements in the DS. In fact, increases in the total nitrogen and phosphorus in the sandy sediment medium by addition of DS were confirmed, though trace elements were not analyzed. For example, the total nitrogen and phosphorus concentrations in MS were $9.4 \mu \mathrm{g}-\mathrm{N} / \mathrm{g}$ and $210 \mu \mathrm{g}-\mathrm{P} / \mathrm{g}$, while the respective values in DS were 220 $\mu \mathrm{g}-\mathrm{N} / \mathrm{g}$ and $360 \mu \mathrm{g}-\mathrm{P} / \mathrm{g}$ in DS.

The nitrogen:phosphorus ratio of plankton in the oceans is empirically known to be approximately 16:1 by atoms (the Redfield ratio) (Goldman et al., 1979). Here, the total phosphorus in MS was much higher than the total nitrogen. We can hypothesize that it is the enrichment of nitrogen by the addition of DS which is the factor stimulating benthic microalgal growth. Total nitrogen and phosphorus includes the fraction unavailable to benthic. According to the Truog's method, the amount of available phosphorus of MS was determined to be $48.68 \mu \mathrm{g}-\mathrm{P}_{2} \mathrm{O}_{5} / \mathrm{g}(0.44 \mu \mathrm{mol}-\mathrm{P} / \mathrm{g})$. To avoid nitrogen limitation, available nitrogen in MS should be more than $7.0 \mu$ mol-N/g (based on the Redfield ratio). Even if the total nitrogen of MS is assumed to be available for benthic microalgae, the amount is only $9.4 \mu \mathrm{g}-\mathrm{N} / \mathrm{g}(0.67 \mu \mathrm{mol}-\mathrm{N} / \mathrm{g})$, which is much lower than the threshold for nitrogen limitation. In contrast, the total nitrogen in DS was 220 $\mu \mathrm{g}-\mathrm{N} / \mathrm{g}(15.7 \mu \mathrm{mol}-\mathrm{N} / \mathrm{g})$, exceeding the threshold. These results support the hypothesis that the stimulated benthic algal growth in the artificial tidal flats was due to enrichment of nitrogen by addition of DS.

\section{Growth tests of a short neck clam in MS/UT-DS}

Figure 8 shows the changes in the survival and shell length elongation percentages of the short neck clam $R$. philippinarum. It survived in the mixtures of MS and DS as well as MS itself, however, its growth was dependent on the mixing ratio of DS. At $5 \%$ silt and clay, the liability and shell length increase of $R$. philippinarum were similar to that in MS, whereas a lower shell length increase was observed at $10 \%$ silt and clay. One possible reason for this might be chemical constituents such as sulfides present in DS, although these were not analyzed. Although too much DS may suppress the growth of $R$. philippinarum, the result indicates that $R$. philippinarum can grow in artificial tidal flats to which DS is added.

This experiment was carried out on a laboratory scale, and possibly the test system was sensitive to the chemical constituents of DS due to lack of tidal wave action. To determine the acceptable mixing ratio of DS, further studies should be conducted under tide wave action. 


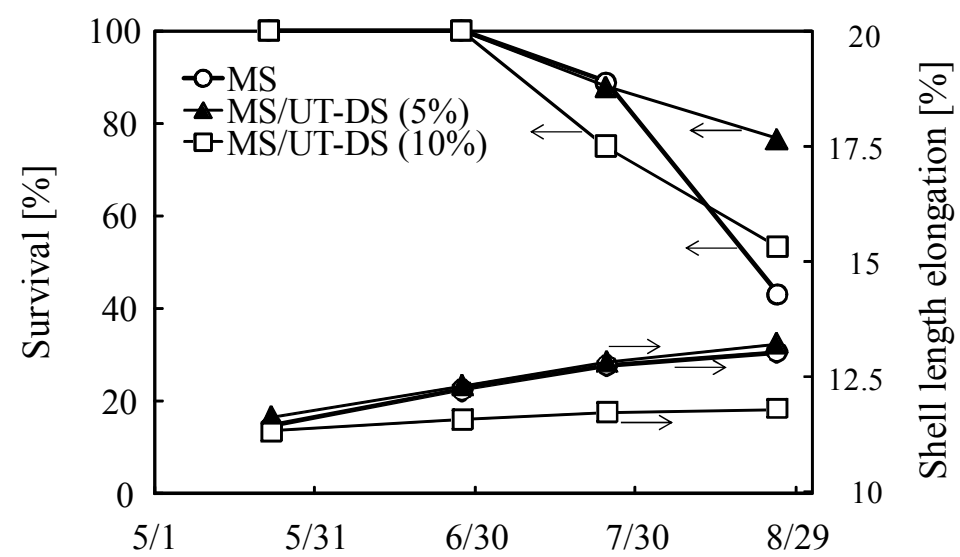

Fig. 8 Survival and shell length elongation percentages of a short neck clam $R$. philippinarum during the experimental period.

\section{CONCLUSIONS}

In this study, artificial tidal flats were constructed in the real seashore and in a tidal flat simulator using dredged sediment (DS) as a silt and clay source, and the benthic ecosystems were analyzed. Results in both experiments consistently indicated that DS could be used for construction of artificial tidal flats, regardless of the granulation treatment of DS. Furthermore, the tidal flat simulator experiment showed that the DS addition increased macrobenthos abundance. Use of a conditioner made of paper sludge and poly-aluminum chloride, however, caused a lag time for the growth of macrobenthos, possibly because these agents may be released during the experimental period. Possible reasons for the increased polychaete and gastropod abundances in the artificial tidal flats might be the enrichment of organic matter and stimulation of benthic microalgae by addition of DS. The growth test for a short neck clam showed that $R$. philippinarum can grow in artificial tidal flats to which DS is added, although too much DS may suppress its growth. The data presented here indicates that DS may be a good sediment additive for the construction of artificial tidal flats.

\section{REFERENCES}

Ali F. and Nakamura K. (1999) Effect of temperature and relative humidity on the tolerance of the Japanese clam, Ruditapes philippinarum (Adams \& Reeve), to air exposure, Aquacul. Res., 30, 629-636.

Bolam S. G., Whomersley P., and Schratzberger M. (2004) Macrofaunal recolonization on intertidal mudflats: effect of sediment organic and sand content, J. Exp. Mar. Biol. Ecol., 306 (2), 157-180.

Brown A. C. and McLachlan A. (1990) Ecology of sandy shores. Elsevier, Amsterdam.

Bruland G.L., Grunwald S. Osborne T.Z., Reddy K.R., and Newman S. (2006) Spatial distribution of soil properties in water conservation area 3 of the everglades, Soil Sci. Soc. Am. J., 70(5), 1662-1676.

Day J.W., Hall A. S., Kemp W. M., and Yanez-Arancibia A. (1989) Estuarine ecology. Wiley, New York.

Evans P. R., Ward R. M., Bone M., Leakey M. (1998) Creation of temperate-climate intertidal mudflats: factors affecting colonization and use by benthic invertebrates and their bird predators, Mar. Pollut. Bull., 37 (8-12), 535-545.

Herman P. M. J., Middelburg J. J., Van de Koppel J., Heip C. H. R. (1999) Ecology of 
estuarine macrobenthos. Adv. Ecol. Res., 29, 195-240.

Hosokawa Y. (1997) Restoration of coastal tidal flat in Japan. In US-Japan experts meeting on the management of bottom sediment containing toxic substances, 1-8.4-7 November 1997, Kobe, Japan.

Imai D., Kato T., Dabwan A., and Harada I. (2006) Development of technology for reproducing of marine environment from dredged sediments by using paper sludge ash and its beneficial applications for cleaning Ago Bay, Kami Pa Gikyoshi/Japan Tappi Journal, 60(9), 80-88. (in Japanese)

Ishii R., Sekiguchi H., Nakahara Y., Jinnai Y. (2001) Larval recruitment of manila clam Ruditapes philippinarum in Ariake Sound, southern Japan, Fisher. Sci., 67 (4), 579-591.

Imamura H. (1997) Effective use to the biological habitat creation of the dredged soil, $J$. Water Waste., 39(7), 603-610.

JIS (Japanese Industrial Standards) (2000a) Test method for ignition loss of soils, A 1226:2000, Japanese Standards Association.

JIS (Japanese Industrial Standards) (2000b) Test method for particle size of soils, A 1204:2000, Japanese Standards Association.

Kim Y. H., Bae B., and Choung Y. K. (2005) Optimization of biological phosphorus removal from contaminated sediments with phosphate-solubilizing microorganisms, J. Biosci. Bioengineer., 99(1), 23-29.

Kimura K., Miyoshi Y., Shimazu T., Akazawa Y., and Oshima N. (1992) Decontamination capacity of the artificial seashore. Report of Tokyo metropolitan research institute for environmental protection. pp.89-100. (in Japanese)

Lee J. G., Nishijima W., Mukai T., Takimoto K., Seiki T., Hiraoka K., Okada M. (1997) Comparison for structure and functions of organic matter degradation at natural and constructed tidal flat, Jpn. Soc. Water Environ., 20, 175-184. (in Japanese)

Lee J. G., Nishijima W., Mukai T., Takimoto K., Seiki T., Hiraoka K., and Okada M. (1998) Factors to Determine the Functions and Structures in Natural and Constructed Tidal Flats, Water Res. 32(9), 2601-2606.

Magni P. and Montani S. (2006) Seasonal patterns of pore-water nutrients, benthic chlorophyll a and sedimentary AVS in a macrobenthos-rich tidal flat, Hydrobiol., 571 (1), 297-311.

McConnaugley, T. and McRoy C.P. (1979) Food web structure and the fractionation of carbon isotope in the Bering Sea, Mar. Biol. 53, 57-262.

Ministry of Environment (MOE) of Japan (1999) National Surveys on the Natural Environment, Nature and Parks, Ministry of Environment, Tokyo.

Miyoshi Y., Oshima N., and Kimura K. (1991) Decontamination capacity of the artificial seashore. Report of Tokyo metropolitan research institute for environmental protection. pp.124-137.

MOE (Ministry of Environment of Japan) (1996) Methods and description of bottom sediment survey. Japan Environmental Measurement \& Chemical Analysis Association, Tokyo. (in Japanese)

Morrison M. A., Francis M. P., Hartilla B. W., and Parkinson D. M. (2002) Diurnal and tidal variation in the abundance of the fish fauna of a temperate tidal mudflat, Estuar, Coast. Shelf Sci., 54 (5), 793-807.

Posey M. H., Alphin T. D., and Cahoon L. (2006) Benthic community responses to nutrient enrichment and predator exclusion: Influence of background nutrient 
concentrations and interactive effects, J. Exp. Mar. Biol. Ecol., 330 (1), 105-118.

Sakamaki, T., Nishimura, O., and Sudo, R., 2006. Tidal time-scale variation in nutrient flux across the sediment-water interface of an estuarine tidal flat, Estuar, Coast. Shelf Sci., 67 (4), 653-663.

The SCOR/UNESCO Working group on Photosynthetic pigments (1966) Monographs on oceanographic methodology, 1, 69.

Tiner R. W., Swords J. Q., and Bergquist H. C. (2003) Wetlands of the Boston harbor islands national recreation area. PB Rep. PB-2006-112502, 40.

Truog E. (1930) The determination of readily available phosphorus in soils, J. Am. Soc. Agron., 23, 874-882.

Woodard H. J. (1999) Plant growth on soils mixed with dredged lake sediment, $J$. Environ. Sci. Health - part A Toxic/hazardous substances and environmental engineering, 34(6), 1229-1252. 